\title{
RECENT ADVANCES IN BLOOD TRANSFUSION: THE USE OF A CONTINUOUS AUTOTRANSFUSION DEVICE IN VASCULAR SURGERY A report on local experience
}

Emma L Thompson, RODP; Steve J Davies, FRCA; Mark B Smith, FRCA

In this article, the authors, two of whom are anaesthetists and one an operating department practitioner, describe their clinical practice and the use of the intra-operative Continuous Auto Transfusion System (CATS) machine in abdominal aortic surgery at the Royal Lancaster Infirmary (RLI). They compare outcomes between those patients who received banked blood and those who received blood from the CATS machine in an open series of patients reflecting current practice. The data demonstrate significant cost savings in patient management.

\section{INTRODUCTION}

During some surgical procedures patients can lose substantial amounts of blood.

There are many techniques available to minimise blood loss from peri-operative haemodilution to induced hypotension. Once the blood is lost from the circulation cell salvage is a system which can return the patient's own blood during the operation. This can reduce the need to give donated blood. Combining this technique with a re-evaluation of haemoglobin threshold for transfusion is enabling major surgery to be completed without blood transfusion.

Red blood cells transport oxygen to the tissues using haemoglobin. A low haemoglobin concentration due to excessive blood loss will result in reduced oxygen delivery to tissues which can cause morbidity, mortality and a functional impairment in the peri-operative period.

Maintenance of an adequate haemoglobin concentration by transfusions of blood is, therefore, necessary in patients who have a large blood loss. This is essential if there is pre-existing organ dysfunction.

Using a patient's own blood to maintain circulating volume and an adequate haemoglobin is called autologous blood transfusion. The term allogenic blood transfusion refers to the use of donated blood being used on a different recipient.

There are different forms of autologous transfusion:

- Pre-deposit autologous donation. The patient donates blood at intervals before the operation - usually over several weeks - which is then stored and used during surgery. Cross match errors and storage complication are not avoided.

- Acute normovolaemic haemodilution. Whole blood is collected immediately prior to surgery, while the patient is in theatre. At the same time intravenous fluids are given to maintain the circulating volume in the body (normovolaemia).
- Intra-operative cell salvage. Blood lost during surgery is collected, processed and returned to the patient during the operation or the immediate peri-operative time.

- Postoperative cell salvage. Blood is collected from surgical drains after surgery and transfused back to the patient. This process has been used in certain orthopaedic and thoracic procedures.

Only intra-operative cell salvage will be discussed in this article. At the RLI, the intra-operative cell salvage device used is CATS.

\section{RISKS OF ALLOGENIC TRANSFUSION AND THE POSSIBLE BENEFITS OF AUTOLOGOUS TRANSFUSION}

\section{a) Medical risks}

More stringent screening of blood donors and improved testing procedures on donated blood has resulted in substantial improvements in the safety of blood supplied. However, risks are still present in the use of non-autologous blood (table 1). These risks are small in absolute terms, but are shown for comparison with the risks of other events occurring naturally and which do exercise the minds of many patients. We believe, therefore, that these risks are not insignificant.

\begin{tabular}{|l|l|}
\hline Dying of natural causes at 40 years old & $1: 5,000$ \\
\hline Blood transfusion reaction & $1: 12,000$ \\
\hline Viral disease transmission & $\begin{array}{l}1: 100,000 \text { to } \\
1: 1,000,000 \\
\text { (data from the USA) }\end{array}$ \\
\hline Bacterial infection from blood transfusion & $1: 400,000$ \\
\hline Winning the National Lottery (6 numbers) & $1: 14,000,000$ \\
\hline \multicolumn{2}{|c|}{ Table 1 Risks in blood transfusion and life in general } \\
\hline
\end{tabular}

Despite human blood in the United Kingdom (UK) being donated free of charge, it becomes expensive due to handling, cross matching, storage and the delivery process. Donated blood is in short supply, antigenic, has a limited shelf life, requires a storage facility and carries the risk of disease transmission.

As autologous blood is immunosuppressive it may independently increase the risk of infection after trauma and surgery. 
Some religious groups will not accept donated blood transfusions but may accept autologous blood if a continuous circle is maintained.

\section{b) Economic factors}

The cost of a unit of blood is approximately $£ 130$. The cost of fresh, frozen plasma and platelets is comparable.

The cost of the disposable part of the CATS is about $£ 110$.

If the transfusion of one unit of allogenic blood is 'saved' then, by an equivalent amount of salvaged blood, CATS becomes economical. The potential cost savings are related to the amount of blood saved and any reduction in length of stay in hospital due to avoided complications.

\section{ADVANTAGES OF INTRA-OPERATIVE CELL SALVAGE}

There are significant clinical advantages of using a cell salvage system:

- fresh red cells that would otherwise be lost are re-infused

- it provides a ready supply of blood that is available in proportion to the losses that are occurring

- it may reduce the use of allogenic blood and risks associated with its use

- it should be associated with no risk of clerical error

- it is acceptable by some Jehovah's Witnesses

- the technique has low complication rates

\section{DISADVANTAGES OF INTRA-OPERATIVE CELL SALVAGE}

- restricted use in malignancy, contaminated fluids, sickle cell anaemia

- the aspiration of procoagulants (eg amniotic or ascetic fluid, haemostatic agents) into the reservoir presents a theoretical risk

- with large volume losses there is a risk of dilutional coagulopathy as coagulation factors and platelets are lost

- training required to use

\section{CELL SALVAGE}

There are at least four techniques of red cell salvage:

- centrifugal processors

- haemofiltration processors

- single reinfusion

- mediastinal reinfusion devices

CATS collects blood via the surgical suction into a reservoir. When an amount of blood has been collected it can be processed. This involves a centrifugal chamber in which the red blood cells are separated form the other blood components and washed with a saline solution. The concentrated and cleansed red blood cells are then given back to the patient.

CATS removes impurities and activated coagulation factors, and can separate fat droplets from blood. It haemoconcentrates the returnable blood to a haematocrit of $50-70 \%$.

\section{WHEN TO USE}

Intra-operative cell salvage should be considered when the anticipated surgical blood loss exceeds $500 \mathrm{ml}$ or greater than $10 \%$ total blood volume. This loss would suggest a requirement of a 2 allogenic blood unit transfusion. It can be used in elective and emergency surgery. Within surgical procedures, blood losses may vary so clinical judgement is required.

Where blood losses are variable for a given operation, it is possible to use the suction system of the cell salvage and use the collecting reservoir alone, thereby reducing the costs of the apparatus used for centrifugation. A decision to process the collected blood can be made later.

\begin{tabular}{|c|c|}
\hline Orthopaedics & $\begin{array}{l}\text { Major spinal reconstructions } \\
\text { Revision joint replacement }\end{array}$ \\
\hline Cardiac & All major procedures \\
\hline General & $\begin{array}{l}\text { Major hepatectomies } \\
\text { Pelvic clearances } \\
\text { Major abdominal/thoracic trauma } \\
\text { Accident and Emergency }\end{array}$ \\
\hline Urology/gynaecology & $\begin{array}{l}\text { Radical cystectomy } \\
\text { Radical prostatectomy } \\
\text { Radical hysterectomy }\end{array}$ \\
\hline Transplant & Liver/heart/lung \\
\hline Vascular & $\begin{array}{l}\text { Elective or emergency aortic } \\
\text { reconstruction }\end{array}$ \\
\hline Jehovah's Witnesses & $\begin{array}{l}\text { All surgical procedures where blood } \\
\text { loss is expected to have an impact }\end{array}$ \\
\hline
\end{tabular}

\section{THE USE OF CATS DURING MAJOR VASCULAR SURGERY}

The recent acquisition of a CATS machine for use during vascular surgery at the RLI gave an opportunity to look at our practice by collating data from theatre and the Intensive Care Unit (ICU).

We collected data on all patients undergoing abdominal aortic surgery between March 2004 and April 2005. There were 54 patients identified including both elective and emergency cases. Some patients underwent surgery with the CATS machine being used, others did not. The decision to use the machine was made by the theatre staff on the day in accordance with existing expertise.

Two patients died during surgery, one was transferred to another hospital's ICU due to a bed shortage and transfusion data on three patients is incomplete.

We collected the following data:

- patient demographics

- blood products used

- length of critical care unit stay

- $\mathrm{PaO}_{2} / \mathrm{FiO}_{2}(\mathrm{P} / \mathrm{F})$ ratio on admission to the ICU

The $\mathrm{PaO}_{2} / \mathrm{FiO}_{2}$ ratio is a simple marker of lung function. $\mathrm{PaO}_{2}$ is the partial pressure of oxygen in arterial blood; $\mathrm{FiO}_{2}$ is the fractional inspired concentration of oxygen. The ratio relates to the diffusion of oxygen across the alveolar membrane and disruption due to lung water, atelectasis and hypoperfusion. 


\section{HISTORY OF TRANSFUSION}

1492 - Pope Innocent VIII had an apoplectic stroke; became weak and went into a coma. His physician advised a blood transfusion as a therapeutic measure for the Pope's illness. The Pope did not benefit and died by the end of that year.

1615 - Andreas Libavius described his technique of blood transfusion. It was unfortunately not adequately publicised.

1628 - English physician William Harvey (1578-

1657) described the functions of the heart and the circulation of blood.

1665 - The first blood transfusions of record take place. Animal experiments conducted by Richard Lower, an Oxford physician, started as dog-to-dog experiments and proceeded to animal-to-human over the next two years. Dogs were kept alive by the transfusion of blood from other dogs.

1667 - Jean-Baptiste Denis in France reported successful transfusions from sheep to humans.

1678 - Transfusion from animals to humans, having been tried in many different ways, was deemed to be unsuccessful, and was subsequently outlawed by the Paris Society of Physicians because of reactions, many resulting in death.

1795 - In Philadelphia, an American physician, Philip Syng Physick, performed the first known human blood transfusion, although he did not publish the particulars.

1818 - James Blundell, a British obstetrician, performed the first successful transfusion of human blood to a patient for the treatment of postpartum haemorrhage. Using the patient's husband as a donor, he extracted a small amount of blood from the husband's arm and, using a syringe, he successfully transfused the wife. Between 1825 and 1830 , he performed ten documented transfusions, five of which proved beneficial to his patients, and published these results. He also devised various instruments for performing blood transfusions.

1840 - In London, Samuel Armstrong Lane performed the first successful whole blood transfusion to treat haemophilia.

1867 - English surgeon Joseph Lister utilised antiseptics to control infection during blood transfusions.

1873 to 1880 - Physicians in the United States (US) are documented, during these years, to have transfused milk (from cows and goats) to humans.

1884 - Saline infusion replaced milk as a 'blood substitute' due to increased frequency of adverse reaction to milk.
1901 - Karl Landsteiner, an Austrian physician, documented the first three human blood groups (based on substances present on the red blood cells), A, B and $O$.

1907 - Reuben Ottenberg performed the first blood transfusion using blood typing and cross matching. Ottenberg also observed the 'Mendelian inheritance' of blood groups and recognized the 'universal' utility of group $\mathrm{O}$ donors.

1908 - French surgeon Alexis Carrel devised a way to prevent blood clotting. His method involved joining an artery in the donor directly to a vein in the recipient with surgical sutures. He first used this technique to save the life of the son of a friend, using the father as donor.

1912 - Roger Lee, a Massachusetts General Hospital visiting physician, demonstrated that blood from all groups can be given to group $A B$ patients.

1914 - Long term anticoagulants, among them sodium citrate, were developed, allowing longer preservation of blood.

1915 - At Mt. Sinai Hospital in New York City, Richard Lewisohn used sodium citrate as an anticoagulant which was to transform transfusion procedure from one that had to be performed with both the donor and the receiver of the transfusion in the same place at the same time, to the blood banking system in use today. At the same time, R. Weil demonstrated the feasibility of refrigerated storage of such anticoagulated blood.

1916 - Francis Rous and JR Turner introduced a citrate-glucose solution that permitted storage of blood for several days after collection in containers for later transfusion. This discovery directly led to the establishment of the first blood 'depot' by the British during World War I.

1926 - The British Red Cross instituted the first human blood transfusion service in the world.

1932 - The first facility functioning as a blood bank was established in a Leningrad hospital.

1939 and 1940 - The Rh blood group system was discovered by Karl Landsteiner, Alex Wiener, Philip Levine and RE Stetson and was recognised as the cause of the majority of transfusion reactions. Known as the Rhesus (Rh) system, once this reliable test for this grouping had been established, transfusion reactions became rare. Identification of the Rh factor has stood next to $A B O$ as another important breakthrough in blood banking.

1940 - Edwin Cohn, a professor of biological chemistry at Harvard Medical School, developed a cold ethanol fractionation; the process of breaking down plasma into components and products. 


\section{HISTORY OF TRANSFUSION}

1941 - Isodor Ravdin, a prominent surgeon from Philadelphia, effectively treated victims of the Pearl Harbor attack with Cohn's albumin for shock.

1943 - The introduction by JF Loutit and PL Mollison of acid citrate dextrose (ACD) solution permitted transfusions of greater volumes of blood and longer term blood storage.

1943 - P Beeson published the classic description of transfusion-transmitted hepatitis.

1945 - Coombs, Mourant and Race described the use of antihuman globulin (the 'Coombs Test') to identify 'incomplete' antibodies.

1950 - Carl Walter and WP Murphy Jr introduced the plastic bag for blood collection. Replacing breakable glass bottles enabled the evolution of a collection system capable of safer and easier preparation of multiple blood components from a single unit of whole blood.

1953 - Development of the refrigerated centrifuge began to further expedite blood component therapy.

1954 - The blood product Cryoprecipitate (now AHF) was developed for people suffering from haemophilia.

1954 to 1958 - Products made from blood plasma were developed to treat diseases such as chicken pox.

1959 - Max Perutz of Cambridge University deciphered the molecular structure of haemoglobin, the molecule that transports oxygen and gives red blood cells their colour.

1962 - The first antihaemophilic factor (AHF) concentrate to treat coagulation disorders in haemophilia patients was developed through the process of fractionation.

1967 - Rh immune globulin was commercially introduced to prevent $\mathrm{Rh}$ disease in the newborns of Rh-negative women.

1969 - S Murphy and F Gardner demonstrated the feasibility of storing platelets at room temperature, which revolutionised platelet transfusion therapy.

1971 - Hepatitis B surface antigen (HBsAg) testing of donated blood began in the US.

1972 - Aphaeresis was used to extract one cellular component, returning the rest of the blood to the donor.

1974 - First available cell salvage machine commercially available.

1979 - A new anticoagulant preservative, CPDA-1, which extends the shelf life of whole blood and red blood cells to 35 days, increasing the blood supply and facilitating resource sharing among blood banks is introduced.

1983 - Newly introduced blood additive solutions resulted in extended shelf life of treated red blood cells to 42 days.

1985 - The first blood screening test to detect the probable presence of HIV was licensed and implemented by blood banks in the US.

1987 - Two tests for screening for indirect evidence of hepatitis $C$ were developed and implemented: hepatitis B core antibody (anti-HBc) and the alanine aminotransferase test (ALT).

1989 - In the US, human T Iymphotropic virus antibody (anti-HTLV-I) testing of donated blood began.

1990 - The first specific test for hepatitis $C$ was introduced. This is a major cause of 'non-A, non-B' hepatitis. (The hepatitis $\mathrm{C}$ virus, HCV, has, as of the date of this writing, not been isolated.)

1992 - Testing of donor blood for HIV-1 and HIV-2 antibodies (anti-HIV-1 and anti-HIV-2) was implemented.

1996 - Testing of donated blood for the HIV p24 antigen began. The test did not do a complete job, but improved on the previous tests, in that the time taken to clear donated blood for use was shortened substantially.

1999 - The blood manufacturing community began implementation of Nucleic Acid Amplification Testing (NAT). NAT employs a testing technology that directly detects the genetic materials of viruses like HCV and HIV.

\section{CATS machine: the future?}

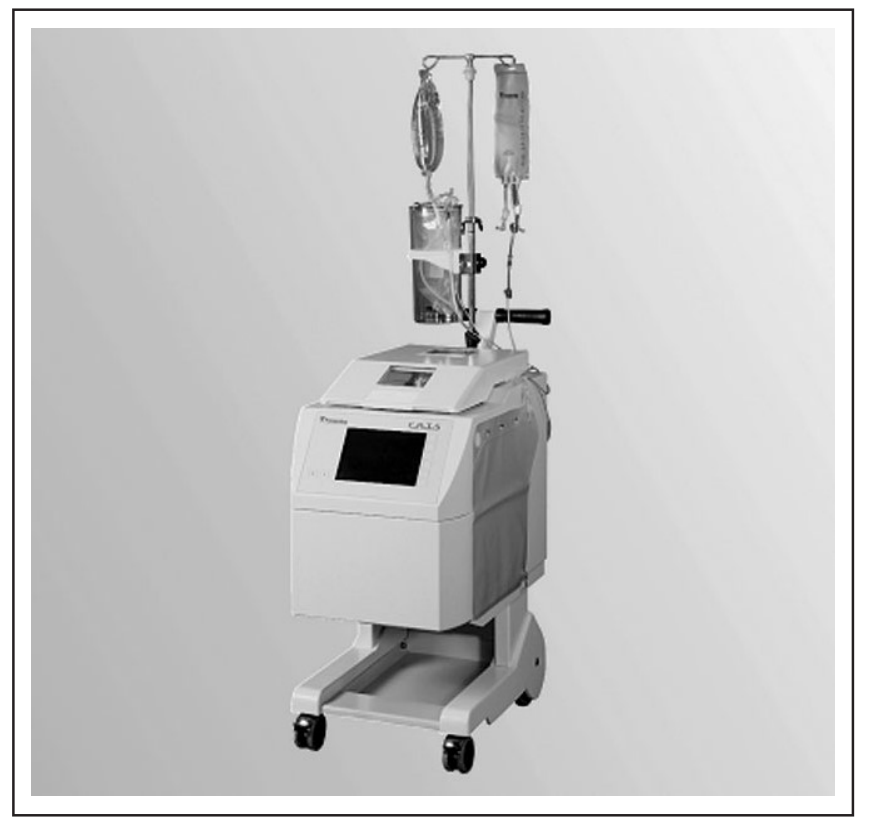


The data was collected from theatre records, CATS audit, transfusion service records and the local Intensive Care National Audit and Research Centre (ICNARC) database.

\section{RESULTS}

The data can be presented in tabular form.

a) Case mix

\begin{tabular}{|l|c|c|c|}
\hline & CATS used & CATS not used & Total \\
\hline Elective cases & 28 & 7 & 35 \\
\hline Emergency cases & 6 & 13 & 19 \\
\hline Total & 34 & 20 & 54 \\
\hline
\end{tabular}

\section{b) Elective cases}

\begin{tabular}{|l|c|c|c|c|}
\hline Blood product & \multicolumn{2}{|c|}{ CATS used } & \multicolumn{2}{c|}{ CATS not used } \\
\hline Units transfused & $\begin{array}{c}28 \\
\text { patients }\end{array}$ & $\begin{array}{c}\text { Units per } \\
\text { patient }\end{array}$ & $\begin{array}{c}7 \\
\text { patients }\end{array}$ & $\begin{array}{c}\text { Units per } \\
\text { patient }\end{array}$ \\
\hline Red cells & 31 & 1.107 & 10 & 1.43 \\
\hline Platelets & 3 & 0.107 & 0 & 0 \\
\hline Fresh frozen plasma & 20 & 0.714 & 0 & 0 \\
\hline
\end{tabular}

\section{c) Emergency cases}

\begin{tabular}{|l|c|c|c|c|}
\hline Blood product & \multicolumn{2}{|c|}{ CATS used } & \multicolumn{2}{c|}{ CATS not used } \\
\hline Units transfused & $\begin{array}{c}6 \\
\text { patients }\end{array}$ & $\begin{array}{c}\text { Units per } \\
\text { patient }\end{array}$ & $\begin{array}{c}13 \\
\text { patients }\end{array}$ & $\begin{array}{c}\text { Units per } \\
\text { patient }\end{array}$ \\
\hline Red cells & 42 & 7 & 168 & 13 \\
\hline Platelets & 0 & 0 & 18 & 1.5 \\
\hline Fresh frozen plasma & 0 & 0 & 70 & 5.5 \\
\hline
\end{tabular}

\section{d) Number of patients requiring transfusion}

\begin{tabular}{|l|c|c|}
\hline Blood product & Elective patients & $\begin{array}{c}\text { Emergency } \\
\text { patients }\end{array}$ \\
\hline Red cell & 11 & 17 \\
\hline Platelet & 3 & 10 \\
\hline Fresh frozen plasma & 5 & 10 \\
\hline Total cases & 35 & 19 \\
\hline
\end{tabular}

\section{e) Average length of ICU stay in days}

\begin{tabular}{|l|c|c|}
\hline & CATS used & CATS not used \\
\hline Elective cases & 2.9 & 1.7 \\
\hline Emergency cases & 5.7 & 9.6 \\
\hline All cases & 3.4 & 6.3 \\
\hline
\end{tabular}

The average $\mathrm{P} / \mathrm{F}$ ratio for patients where CATS used was 38.5 ; where not used it was 46.2.

The average usage of blood and blood products is shown graphically in table 3 .

\section{DISCUSSION}

This article is a description of clinical activity in the vascular theatre, pulling together data routinely collected in theatre and ICU. It is not research, nor an audit and is intended to inform the medical community as to what we do. We have used the data to make some observations and suggestions.

We have examined the use of the CATS machine in abdominal aortic surgery, the effects on blood usage and the effects in ICU.

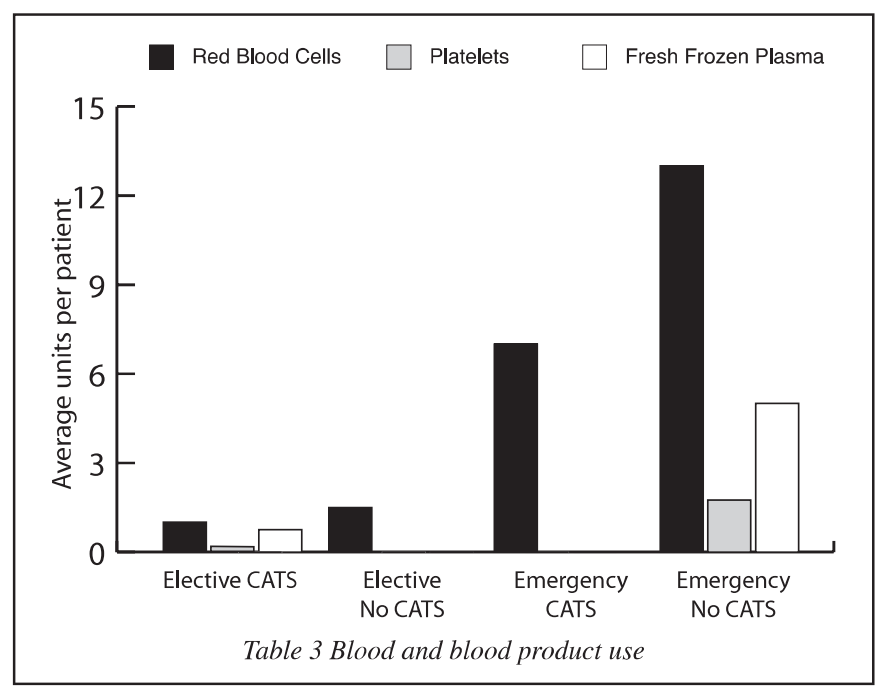

Despite the small number of cases, we think that we have shown a marked reduction in the use of blood and blood products during abdominal aortic surgery, especially with emergencies when CATS is used.

We note the reduction in ICU length of stay when CATS is used. If the $\mathrm{P} / \mathrm{F}$ ratio is accepted as a marker of lung function postoperatively, we think we have shown an improvement of lung function in patients where CATS is used and allogenic blood and blood product transfusions are less. This may be the cause for a reduction in the length of ICU stay. We would argue that improved lung function increases oxygen delivery to tissues, improves organ function and healing. This will encourage earlier ICU discharge.

There is presently one CATS machine at the RLI. It is predominantly used for elective aortic surgery because of the limited number of staff trained in its use. However, CATS may be used with emergency cases that occur within normal working hours if trained staff are available. For cases out of hours, the CATS machine may not be available.

Increasing the number of staff who can operate the machine would be beneficial. Abdominal aortic surgery is undertaken out of hours and we believe that the availability of the apparatus and staff to operate it is an important aspect of providing a comprehensive vascular surgical service.

We have made a saving of 0.5 units of blood during elective cases and 5 units per emergency. The saving on blood products is even greater. We calculate that during this time period we have saved $£ 10,000$ on blood and blood products for emergency surgery. Perhaps of more significance is the three days per patient in ICU that has been avoided. This equates to 150 patient bed days, saving $£ 150,000$ per year.

Cell salvage should be made available for other surgical procedures. Its use should be considered where blood loss is expected to exceed $500 \mathrm{ml}$ or significant blood loss will not be 
tolerated by the patient. The National Institute for Clinical Excellence is currently examining intra-operative blood cell salvage in obstetrics.

\section{SUMMARY}

We have looked at our practice of blood and blood products during abdominal aortic surgery. We have shown that using CATS reduces blood and blood product use, probably reduces the impact of allogenic blood transfusion on lung function, reduces the length of stay in ICU and has significant cost savings.

\section{ACKNOWLEDGEMENTS}

We would like to thank Courtney Spinks, Haemotology Nurse Specialist and Mark Longworth, ICNARC Co-ordinator.

\section{FURTHER READING}

Freischlag JA. Intraoperative cell salvage in vascular surgery worth the effort? Critical Care 2004;8(Suppl 2):S53-S56

National Institute for Clinical Excellence. Interventional Procedures Consultation Document - Intraoperative blood cell salvage in obstetrics. December 2004. London

McGill N, O’Shaughnessy D, Pickering R, Herbertson M, Gill $\mathrm{R}$. Mechanical methods of reducing blood transfusion in cardiac surgery: randomised control trial. $\mathrm{Br}$ Med J 2002;324:1299

Napier JA, Bruce M, Chapman J, et al. Guidelines for autologous transfusion. II. Perioperative Haemodilution and cell salvage. British Committee for Standards in Haematology Blood Transfusion Task Force. Autologous Transfusion Working Party. Br J Anaesth 1997;78(6):768-771

National Blood Conservation Strategy Report - January 2004 